\title{
Empirical Research on Innovation Cluster Area Planning Based on Collaborative Innovation Theory
}

\author{
Yuye Zhou*, Yukun Li, Yi Wang \\ Department of Regional and Urban Planning, Zhejiang University, Hangzhou, P. R. China \\ Email address: \\ zyy2016@zju.edu.cn (Yuye Zhou),3160105892@zju.edu.cn (Yukun Li),3160105883@zju.edu.cn (Yi Wang) \\ ${ }^{*}$ Corresponding author
}

To cite this article:

Yuye Zhou, Yukun Li, Yi Wang. Empirical Research on Innovation Cluster Area Planning Based on Collaborative Innovation Theory. Urban and Regional Planning. Vol. 4, No. 4, 2019, pp. 152-161. doi: 10.11648/j.urp.20190404.14

Received: November 3, 2019; Accepted: December 11, 2019; Published: December 12, 2019

\begin{abstract}
Innovation has become one of the main driving forces of social and economic development, and innovation clusters are crucial supporters for innovative development. Introducing collaborative innovation theory, this paper proposes an important mechanism for the implementation of innovation, and it has theoretical guiding significance for the interpretation and optimization of the spatial effects of innovation clusters. Based on an analysis of the operational mechanisms of collaborative innovation, we explain the formation mechanism and spatial law of innovation clusters from the aspects of innovation environment, innovation subject and collaborative innovation relationship. Then, taking the Dream Town of the Yuhang District in Hangzhou, China, as an example, this paper studies the mechanism of collaborative innovation effects, specifically in physical space design and policy making. With the goal of promoting innovative development, this paper analyzes the influencing factors and mechanisms of the collaborative innovation effect from the aspects of strategic orientation, knowledge integration and innovation and environmental collaboration. At the same time, it summarizes the existing problems of the base, and proposes three aspects: policy orientation, university cooperation and space optimization. The corresponding optimization strategy aims to drive the synergistic innovation effect from the aspects of space and policy, and to provide the impetus for the economic development of the innovation cluster. Through collaborative innovation, we can form a better protection and support environment for innovation subjects, and each of them can break the boundaries of departments, units and industries to achieve the optimal allocation of innovative resources. Collaborative innovation theory is an important theoretical tool to explain the development mechanism and cooperation mode of the innovation cluster area, and also has important guiding significance for the physical planning and construction of innovation clusters.
\end{abstract}

Keywords: Innovation Cluster, Collaborative Innovation, Empirical Research

\section{Introduction}

To solve the problems of social and economic development and to promote industrial transformation and upgrading around the world, innovation and development are generally regarded as important research contents. At the same time, as a spatial carrier of innovation and development, the innovation cluster has also become an important consideration in planning and construction in various places.

At present, academic research on the functional mechanism of innovation agglomeration and on the development of innovation clusters is still lacking, is not systematic, and lacks theoretical research methods.
Introducing collaborative innovation theory, this paper proposes an important mechanism for the realization of technological innovation, and it has theoretical guiding significance for the interpretation and optimization of the spatial effects of innovation clusters.

This paper empirically analyzes the material space planning and policy design of the Dream Town in the Yuhang District of Hangzhou in Zhejiang Province of China, studies the implementation of collaborative innovation theory in the planning and management of its innovative agglomeration area, summarizes the key organizational mechanism of collaborative innovation in the innovation cluster area, and proposes a strategy for planning optimization. The paper holds great significance for guiding research and practice 
regarding relevant development planning and for accelerating the development of innovation worldwide.

\section{Theoretical Research}

\subsection{Conceptual Interpretation}

\subsubsection{Coordination}

The theory of coordination was first proposed by the famous physicist Hermann Haken in the 1970s. Coordination refers to mutual cooperation between the subsystems and departments in a system to achieve a virtuous circle,[1]. This is mainly used to explain the position of two or several parties and the role of mutual force, mutual support and mutual cooperation, focusing on the cooperation between various subsystems and departments within the system and thus having a new structure and function, [2].

\subsubsection{Collaborative Innovation}

Since the 1980s, with the increasing contribution of science and technology to economic development, the idea of collaboration has been valued in the theory of innovation systems. In innovative activities, the introduction of collaboration can explain the system of technological innovation, helping analyze the collaboration of common technology innovation of various elements. Scholars at the Massachusetts Institute of Technology's Sloan Center first proposed the definition of collaborative innovation. They argue that collaborative innovation is a diversified cooperation between various entities that rely on modern information technology and networks for information sharing for common goals [3].

\subsubsection{Characteristics of Collaborative Innovation}

Collaborative innovation is a new paradigm of innovation. The core lies in management innovation. The key is to form a model of interaction between multiple subjects and the core of enterprises, universities, scientific research institutions and other related subjects, such as the government and financial and intermediary services, to break the barriers of the organization. The aim of this interaction is to promote collaborative innovation at the regional, national and even global levels to achieve the optimal allocation of innovative resources.

Collaborative innovation has two distinct characteristics [4]. The first is integrity. The main bodies and elements of collaborative innovation are not simply superimposed but coupled and collaborative, forming an organic whole of resource sharing, realizing the nonlinear superposition of the system, releasing huge utility, and finally realizing the innovation and common development of the whole system. The second is dynamic. Due to the environmental conditions and various factors of the collaborative innovation system, the old system structure cannot adapt to changes, and the innovation system is required to make adjustments in organizational and innovation strategies to achieve new goals [5].

\subsection{Concept Application}

\subsubsection{Innovation Environment}

An innovation environment refers to a stable regional innovation system formed by enterprises, scientific research institutions and government entities in formal and informal innovation [6]. The innovative cluster area discussed in this paper is one of the important mechanisms of the innovation environment in the spatial model. The planning and design of the innovation cluster should not only stay at the traditional level but also establish a multiparty collaborative organization mechanism with enterprises, scientific research institutions and the government.

\subsubsection{Innovation Subjects}

(1) Enterprises

Enterprises are the core subjects of collaborative innovation. The enterprises in a regional industry mainly include producers, suppliers, sellers, competitors and so on. They are the core of regional industrial technology innovation. The comprehensive innovation capability of diversified enterprises determines the ability of regional industrial technology innovation [7]. At the same time, a regional industry is centered on core enterprises and is linked to a cooperative group through the industrial value chain to jointly carry out technological innovation and to enhance the competitiveness of enterprises and industries.

(2) Research Institutions

Scientific research institutions (including universities) are mainly engaged in basic innovative technology research and knowledge creation, and they carry out industrial key and common technology development. They are important direct participants in industrial technology innovation [8]. Scientific research institutions are upstream of the industrial technology innovation chain, and their innovation capabilities directly affect an industry's ability to innovate. They continue to provide innovative results for enterprises and society and cultivate high-level innovative talents. Scientific research institutions are intellectual resource providers and benefit sharers of industrial technology innovation activities. Through cooperation with industrial system enterprises, they realize the commercialization and industrialization of technological innovation achievements and turn innovation achievements into productivity [9].

(3) Government

First, the government promotes regional industry and technology collaborative innovation by building a platform for cooperation in production, education and research, promoting the transformation of scientific and technological achievements, and incubating entrepreneurial enterprises. Second, the government should formulate institutional arrangements for legal, fiscal, and taxation issues related to technological innovation, continuously improve the external environment for industrial development, and guide enterprises to carry out technological innovation. Third, the government ensures the rational and efficient allocation of innovative elements and resources in the innovation system to ensure the healthy and orderly operation of the regional 
industrial technology innovation system [10].

(4) Intermediaries

Intermediaries participate in industrial technology innovation, but they are not knowledge creators, nor are they applications of knowledge technology. In general, intermediaries include communicators and proliferators of innovative resources such as policies, information, knowledge, capital, and scientific and technological achievements, and they are connectors of innovative entities such as enterprises, universities, research institutions, and government [11]. They provide communication, connectivity, and consulting services for innovative systems that promote the transition from scientific to practical technologies. Intermediaries mainly include consulting companies, talent centers, information centers, industry associations, and platform organizations that provide technology transfer and transactions.

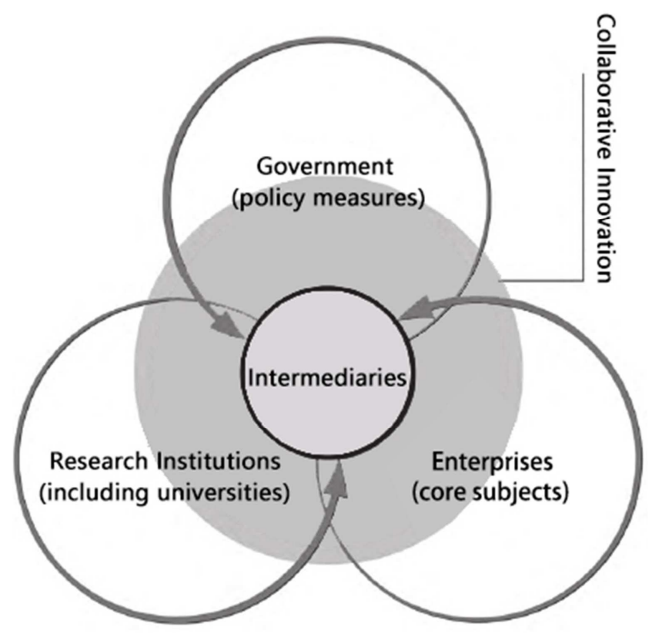

Figure 1. Analysis diagram of the collaborative effects of innovation subjects.

\subsubsection{Collaborative Innovation in Innovation Clusters}

(1) Strategically Oriented Coordination

At the level of strategic development, it is necessary to clarify the collaboration between the various entities, and it is necessary to first clarify the interests of all parties. In innovation activities, enterprises often have an obvious profit orientation and pay attention to economic value; universities and scientific research institutions have a scientific research orientation and pay attention to the academic value of collaborative innovation achievements; the government has a social service orientation and pays attention to the social comprehensive value of collaborative innovation; and financial institutions, etc. have an interest-oriented focus on the new value brought by collaborative innovation [12]. The differences in these concepts and codes of conduct are mutually recognized among the various entities, forming innovative strategic synergies [13]. When formulating policies, we should fully guide the cooperation among various entities to promote innovation.

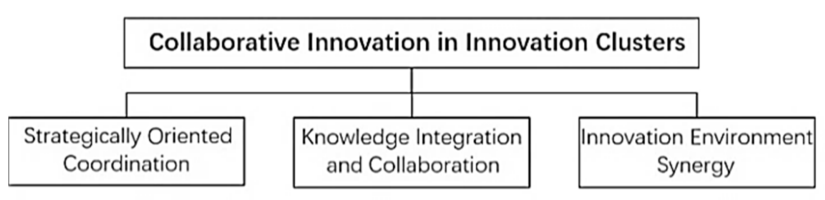

Figure 2. Collaborative innovation in innovation clusters.

(2) Knowledge Integration and Collaboration

At the level of knowledge integration, the knowledge spillover effects of various scientific research institutions should be brought into full play. At the same time, the government should strengthen the guidance of location relations in urban development planning, for example, by adjusting the layout of universities and innovation clusters in cities [14], giving full play to the spatial agglomeration effect, promoting mutual communication, strengthening mutual learning, and building knowledge collaboration platforms, such as industry-university cooperative R\&D centers, engineering research cooperation centers, science parks, incubator gardens, technology industrial zones, and collaborative innovation service organizations [15].

(3) Innovation Environment Collaboration

At the construction level of the innovation environment, it should be clarified that the essence of the planning of the innovation cluster is to promote the healthy development of the innovation collaboration mechanism through urban planning. Planning should focus on providing a collaborative innovation platform and promoting innovation communication [16]. The implementation of the planning and management level of an innovation cluster should promote the exchange space between enterprises and the creation of a collaborative innovation space to ensure the innovative exchange of subjects on both formal and informal occasions. At the same time, for knowledge production institutions, internal interaction and external communication should be strengthened.

\section{Empirical Analysis}

\subsection{Case Overview and Data Sources}

\subsubsection{Overview of the Dream Town}

The Hangzhou Dream Town is located in the Cangqian area in the Yuhang District Future City of Science and Technology in Hangzhou, Zhejiang Province, China. It is east of Hangzhou Normal University, south of Haishu Road and Yuhangtang South Road, north of the Xuanhang Railway, and west of East West Avenue, with the planning encompassing a total area of 347 hectares [17]. Relying on the group of thriving young entrepreneurs in Zhejiang Province, the Dream Town provides a good entrepreneurial environment for young people's dual needs, and it has achieved a new urbanization path based on informatization and the urbanization of people. 


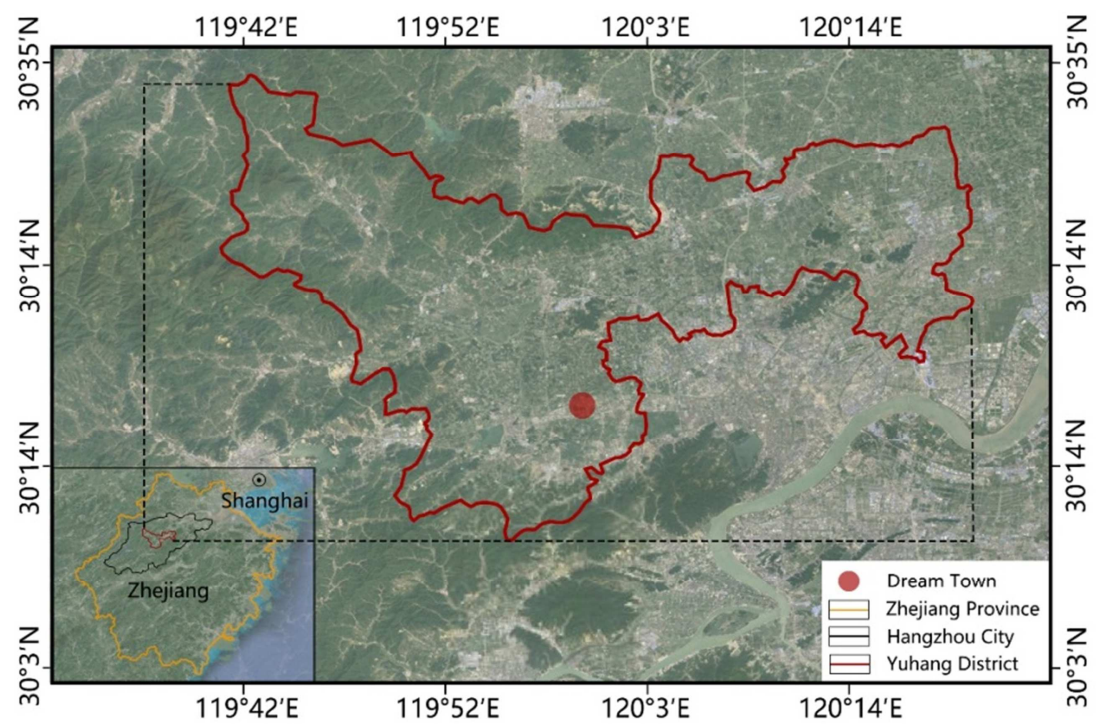

Figure 3. Location of the Dream Town.

In 2014, Hangzhou launched the planning and construction of the Dream Town. From the Yuhang Innovation Base to the overseas high-level talent innovation park, the transformation of the orientation of the planning of the Dream Town is not only a bottom-up innovation gathering and development process but also a planning and practice process that promotes innovation and development through space and policy intervention [18]. Therefore, studying the spatial law and internal mechanism of this process holds certain theoretical and practical significance for understanding the spatial agglomeration characteristics, problems, mechanisms and scientific implementation of innovative cluster planning.

\subsubsection{Research Data Source}

According to the collaborative innovation mechanism, the data collected by this research mainly include the following categories: first, data on the innovative enterprises and their employees, who embody the strategic orientation and collaboration to promote current innovation agglomeration and development; second, data on the willingness of students in Zhejiang University to innovate and start a business, which reflects the trend of knowledge integration and collaboration development; and, third, data reflecting the spatial laws, characteristics and problems of the actual innovation agglomeration process.

At the same time, we obtain subjective data through questionnaires (paper questionnaires and electronic questionnaires) and interviews. We also obtain data related to companies through data collection and network data mining.

\subsection{Analysis of the Collaborative Innovation Effect in the Dream Town}

\subsubsection{Strategically Oriented Coordination}

(1) Building a Platform for Innovation and Entrepreneurship

Relying on the "Great Corridor of Science and Technology in the West of the City", the Dream Town, as an important part of the development of the Hangzhou Science and Technology City in the future, attempts to integrate innovative talents with the surrounding areas, fully links up with platform carriers such as Alibaba headquarters, the Zhejiang Overseas High-level Innovation Park, Zhejiang University, and Hangzhou Normal University, and gathers industrial factors.

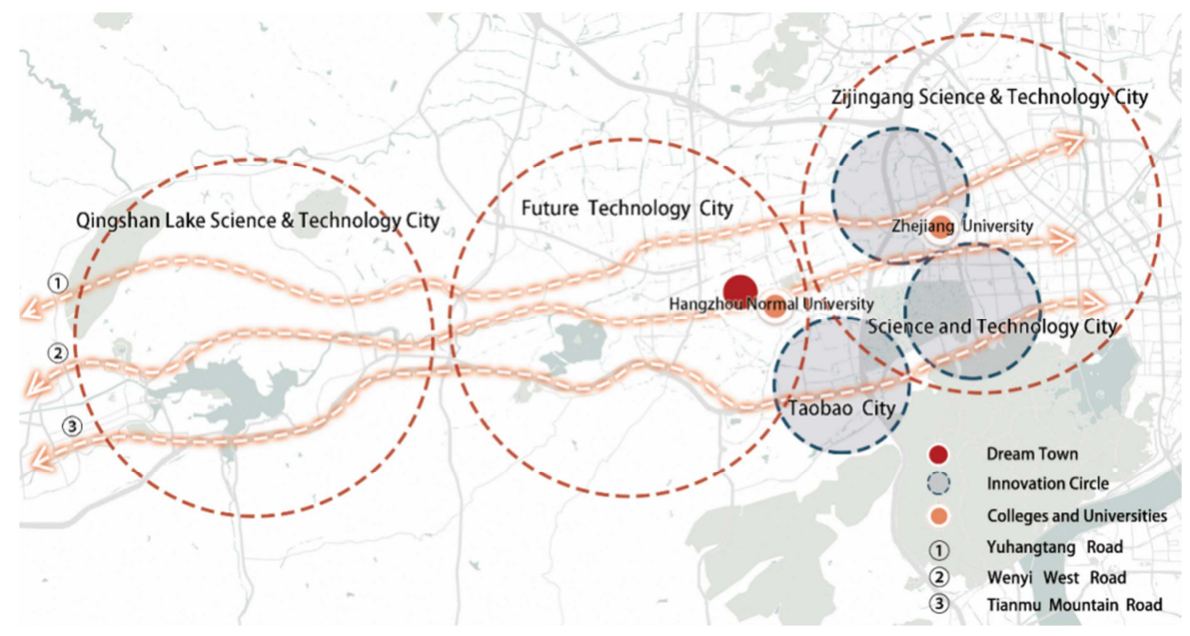

Figure 4. Diagram of the strategically oriented collaboration of the Dream Town. 
(2) Integration of Industry, Education and Research

With the support of government policy, the Dream Town cooperates with Hangzhou Normal University in the construction of the Town Characteristic College (focusing on the construction of the Alibaba Business School, the Hangzhou International Service Engineering College and other pilot colleges of innovation and entrepreneurship), the production, teaching and research base of the small town and the innovation and entrepreneurship base of the small town (the incubator of the Zhejiang University Alumni Association) [19].

In addition to requiring enterprises, scientific research institutions invest their respective advantages and resources. The integration of industry, education and research involve the government, science and technology intermediaries (the seed warehouse in the Dream Town), and financial institutions (angel investment institutions, including Longqi Science and Technology, the Provincial Information Industry Fund and Lujiazui Finance). Among them, enterprises, universities and scientific research institutions carry out technological development, and the government adopts regulations and policies such as the "Hangzhou High-tech Achievements Conversion Fund Management Measures" (Hangzhou Administration Office [2003] 20) and the "Hangzhou Industry-University-Research Cooperation Project Special Fund Funding Management Measures" (Hangzhou Science and Design [2003] 167, Hangzhou Finance and Enterprises [2003] 1028). Guidance and encouragement will be given to science and technology service intermediaries to provide relevant information services (online and offline promotion of innovative tourist competitions, road shows, forums, salons and lectures), and financial institutions will provide financial support to jointly complete technology development and commercialization activities through multiparty collaboration [20].

\subsubsection{Knowledge Integration and Collaboration}

\section{(1) Zhejiang University}

According to the survey, there are 243 cooperation projects between the Dream Town and Zhejiang University, including 26 projects of 500 million yuan and 15 projects of more than 1 million yuan. Zhejiang University mainly concentrates on the fields of biomedicine, advanced manufacturing, electronic information and other industries, sharing its laboratories and technology platforms, jointly building public technology platforms for health care, introducing a scientific and technological literature inquiry system and world patent information service platforms, and jointly promoting the deepening of strategic cooperation between Zhejiang University and Alibaba and the "five-water co-governance" demonstration of paradigm construction, etc. The aim is to create a region from the Zijin Port of Zhejiang University to the Dream Town to the Future City of Science and Technology and to become the most important business card of innovation and entrepreneurship not only in Hangzhou but also in Zhejiang Province.
By investigating the entrepreneurship intention of Zhejiang University students, we found that $43.53 \%$ of these college students have entrepreneurial intentions, and $87.06 \%$ of these college students do not exclude entrepreneurship. Through a cross-analysis of the relationship between the college students' academic qualifications and entrepreneurial intentions, we found that undergraduates have higher entrepreneurial intentions. From this, we can see that it is very necessary to create an entrepreneurial environment, to subsidize venture capital and to provide supporting services for the group of undergraduates who will soon be graduating from or be studying at the university.

Table 1. Zhejiang University students' willingness to start a business.

\begin{tabular}{ll}
\hline Willingness (Grade 1-5) & Porportion \\
\hline 5 (Strong) & $12.35 \%$ \\
4 & $31.18 \%$ \\
3 & $43.53 \%$ \\
2 & $9.41 \%$ \\
1 (Poor) & $3.53 \%$ \\
\hline
\end{tabular}

(2) Hangzhou Normal University

In 2016, Hangzhou Normal University was included in the "2016 National Innovation and Entrepreneurship Typical Experience Colleges" list, and it focuses on the construction of the Alibaba Business School, the Hangzhou International Service Engineering College and other pilot colleges of innovation and entrepreneurship. It is important to promote the cooperative education mechanism of the government, enterprises and other social forces and school innovation and entrepreneurship education, to actively bring into full play the school's geographical advantages from its close proximity to the Zhejiang Future City of Science and Technology and the Dream Town, and to build the "Dream Post" entrepreneurship incubator park with the Hangzhou Future City of Science and Technology Management Committee and other units, from innovation and entrepreneurship education guidance, innovation and entrepreneurship courses. The university engages in the construction and incubation of innovative entrepreneurship projects, the transformation of innovative entrepreneurship achievements and other aspects of in-depth industry-university-research cooperation. For example, seven student enterprises have successfully settled in the "Dream Town" in Zhejiang Province by cooperating with students to build the "Dream Post" and the "Create Customer Space".

Relying on its locational advantages, the university cooperates with enterprises in the Dream Town to carry out the first research and development in university business scenarios, such as rookie automatic driving express robots that can consciously avoid crowds and obstacles, that can go up and down elevators independently, and that can complete the distribution of parcels. Additionally, school libraries, dormitories, canteens and other places have installed face recognition devices. Furthermore, with the $5 \mathrm{G}$ base station, it has become the first university in China with $5 \mathrm{G}+$ wireless network + wired broadband. 


\subsubsection{Innovation Environment Collaboration}

The Dream Town is an innovative and entrepreneurial town with innovative $R \& D$ as its core. It is an area where innovative talents, $R \& D$ institutes and innovative resources are relatively intensive [13]. The Dream Town is required to have forward-looking development and to lead the development of key technologies. The Innovation Science Park has a high demand for innovation environments and platforms. As its material carrier, public space plays an irreplaceably important role.

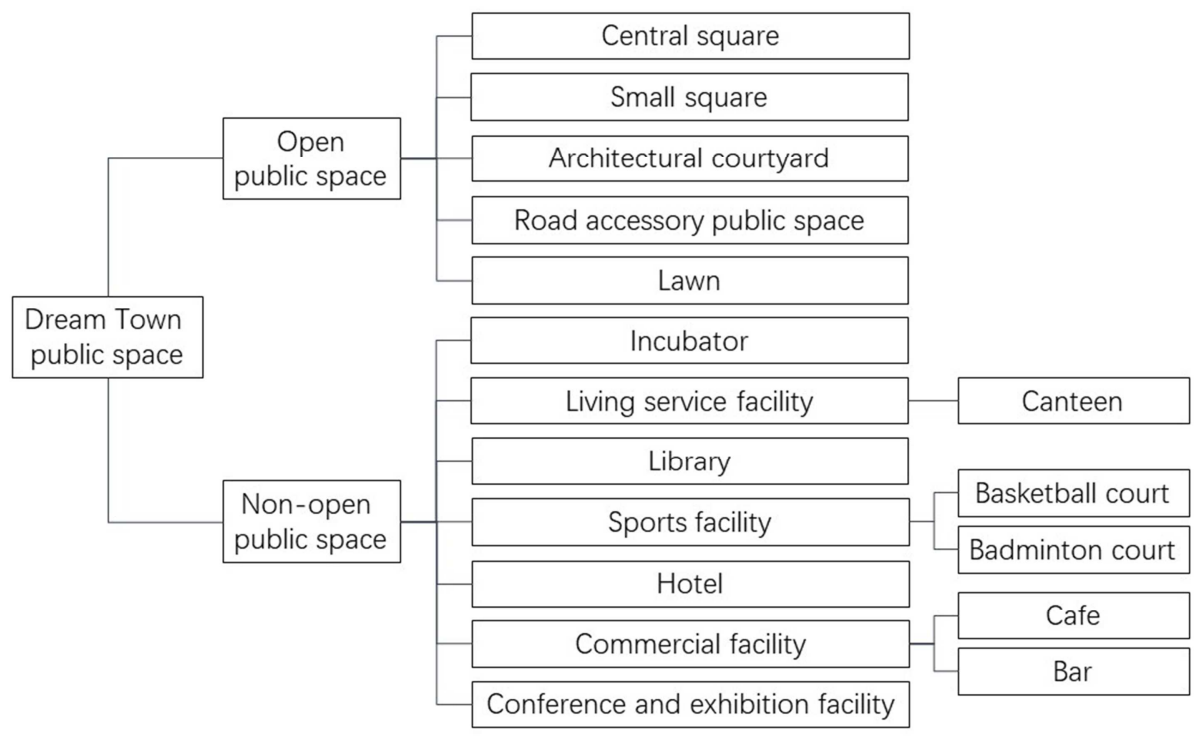

Figure 5. Public space classification of the Dream Town

By providing a good platform for material exchange, public space promotes communication and information exchange among people, relieves and releases the pressure of high-tech talents, and stimulates people's creative inspiration.

(1) Open Public Space

(a) Point space

This space mainly includes node green spaces, parking lots, road intersections, open spaces in front of entries and other small areas of node space that are scattered in the Dream Town. Because the size of the node green spaces is small and they are mostly located in semiprivate office areas, the main users are the staff in the Dream Town $(93.75 \%$ of the staff interviewed). People are satisfied with this kind of public space (Figure 6). In the field survey, it is found that this type of public space is most frequently used in the area and that leisure tables and chairs are often more popular in this type of public space. Angel Village and Yangguo Village have a smaller node space layout. The main service object of public space in the old street in Cangqian is tourists.

(b) Linear space

Linear space can also be called vector space; thus, the concept of "moving" is the main characteristic of this space. Linear space mainly includes lanes, streets, streams, bridges and other spaces for movement, that is, the surrounding space that is a public open space and that can produce changes in human experience. There are many such spaces in the old street of Cangqian. The waterfront trail along the south of the old street of Cangqian provides people with an ornamental linear space. The old street in Cangqian retains the buildings of good quality in the old town in the former Cangqian and uses the design method of slotting needles to add architectural functions in the middle of the old buildings, causing the old street in Cangqian to form an ancient street with different scales and making the linear space interesting. There is also a waterfront linear space in the Internet Village. This linear space is located in the office area. It is used less frequently during office hours. In leisure time, people can walk along the river or have conversations at leisure tables and chairs along the river. It provides a beautiful place for the exchange and collision of inspiration.

(c) Multifaceted space

The main characteristic of multifaceted public open space is that it can provide a place for large-scale social activities. Therefore, the number of such public spaces throughout the Dream Town is low, but the area is large, including all kinds of squares, public green spaces and other places. There are two such public spaces in the old street of Cangqian, namely, the golden wheat field and the Dream Corridor (the water scenic area in the old street of Cangqian), which are equipped with service facilities such as coffee bars and restaurants. When the weather is clear, some staff members often gather to have conversations in the open area of the cafe. In the Angel Village, there is a large square, which is the place where enterprises hold large-scale open-air activities. 


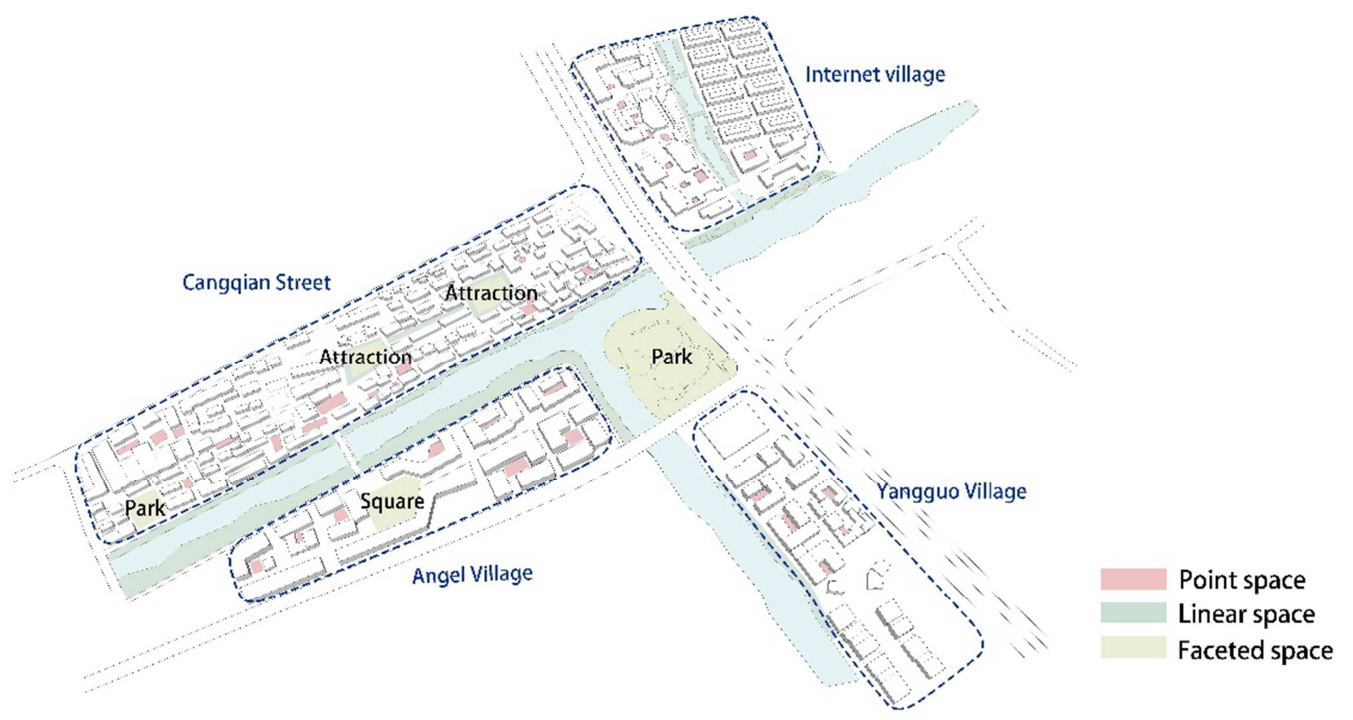

Figure 6. Distribution of open public space in the Dream Town.

(2) Non-open Public Space

Non-open space includes coffee shops, book bar, conference rooms, and lecture halls. In the formal space of the Dream Town, entrepreneurship contests and the lecture series organized by the Creator College are held. In the non-open space of the Dream Town, entrepreneurship salons are held regularly to share successful entrepreneurship experiences, and forums and incubation sharing activities are carried out to enhance entrepreneurship. General informal space can promote innovation exchanges among enterprises, help people feel comfortable and relaxed, and stimulate innovation inspiration.

\subsection{Problems}

\subsubsection{Lack of a School-enterprise Cooperation Platform}

The Dream Town is the cradle of entrepreneurs, but $71.77 \%$ of the 170 college students with entrepreneurial intentions said they did not understand the entrepreneurial services provided by the Dream Town. The survey concluded that the Dream Town did not do well in encouraging college students and did not cause widespread concern among college students.

Table 2. Statistics on the degree of understanding of college students near the Dream Town.

\begin{tabular}{ll}
\hline Degree of understanding & Proportion \\
\hline Very well & $2.94 \%$ \\
Well & $25.29 \%$ \\
Not well & $33.53 \%$ \\
Poor & $38.24 \%$ \\
\hline
\end{tabular}

The college alliance window of the Dream Town facing the university is located in service hall $\mathrm{E}$ of Building 3 of the Internet Village and is listed as a university alliance. The guidance of two departments is mainly accepted. One is the Leading Group Office of the Innovation and Entrepreneurship Education Practice Base of Zhejiang University (Future City of Science and Technology); the other is the university contact window, which is also the station of the Zhejiang University Entrepreneurship College Alliance in the Dream Town [3].

However, the college alliance window is still limited in its work. In its work, the content of the university contact window has stayed more at the level of a contact mechanism and has not yet reached the deep level of cooperation between industry, universities and research institutes. Its work is mainly focused on teaching and educating, internships and site-based learning, and the support it has provided for industry has not been effective. To a certain extent, this is related to the nature of the public service point of the university alliance window, as a result of which it can only assist in solving problems in the industry-university-research cooperation in the role of a proponent of activities of innovation and entrepreneurship. At the same time, the university alliance window is still subject to many factors from reality in the promotion of school-enterprise cooperation. There is still a certain gap between the incubator, enterprises and the campus in the pursuit of innovation and entrepreneurship. There is still room for further exploration.

\subsubsection{Incomplete Supporting Facilities}

The buildings of the Dream Town are interconnected by corridors or platforms, with galleries, overhead floors and staggered platforms along the river, along the street, or along the Garden Square. They blend in with the outdoor landscape to create a rich and varied space for relaxation, providing young artists with an outdoor venue for mutual communication or meditation. At the same time, the internal communication space mainly consists of the creation of crowdfunding, coffee shops, makers and other public spaces in tandem workspaces. Such workspaces provide a platform for information, knowledge, and creative communication between entrepreneurs, between entrepreneurs and investors.

However, based on the questionnaire survey of the town's users, we found that the Dream Town also has the problem of imperfect supporting facilities: (a) The leisure and 
entertainment facilities are insufficient. The town's personnel lack a place to engage in recreational activities during exchanges. (b) The business types around Dream Town are relatively simple. They are mainly convenience stores and catering services, which cannot meet the real-life needs of town users. (c) The parking lot is not properly laid out. Most Internet Village staff members said that the number of parking spaces in the town is insufficient and that it is difficult for customers to park. However, in the course of the field investigation, we found that there is a large underground parking lot and an above-ground parking lot in Yangpan
Village. There are fewer enterprises in Yangpan Village, and there are fewer vehicles in the underground parking lot. It can be seen that the layout of the parking lot in the town is not reasonable, and the scale and demand do not match.

Table 3. Statistics on the frequency of after work activities of staff in the Dream Town.

\begin{tabular}{ll}
\hline After work activity frequency (times/per week) & Proportion \\
\hline$\geq 8$ & $9.38 \%$ \\
$6-7$ & $18.75 \%$ \\
$3-5$ & $31.25 \%$ \\
$0-2$ & $40.63 \%$ \\
\hline
\end{tabular}

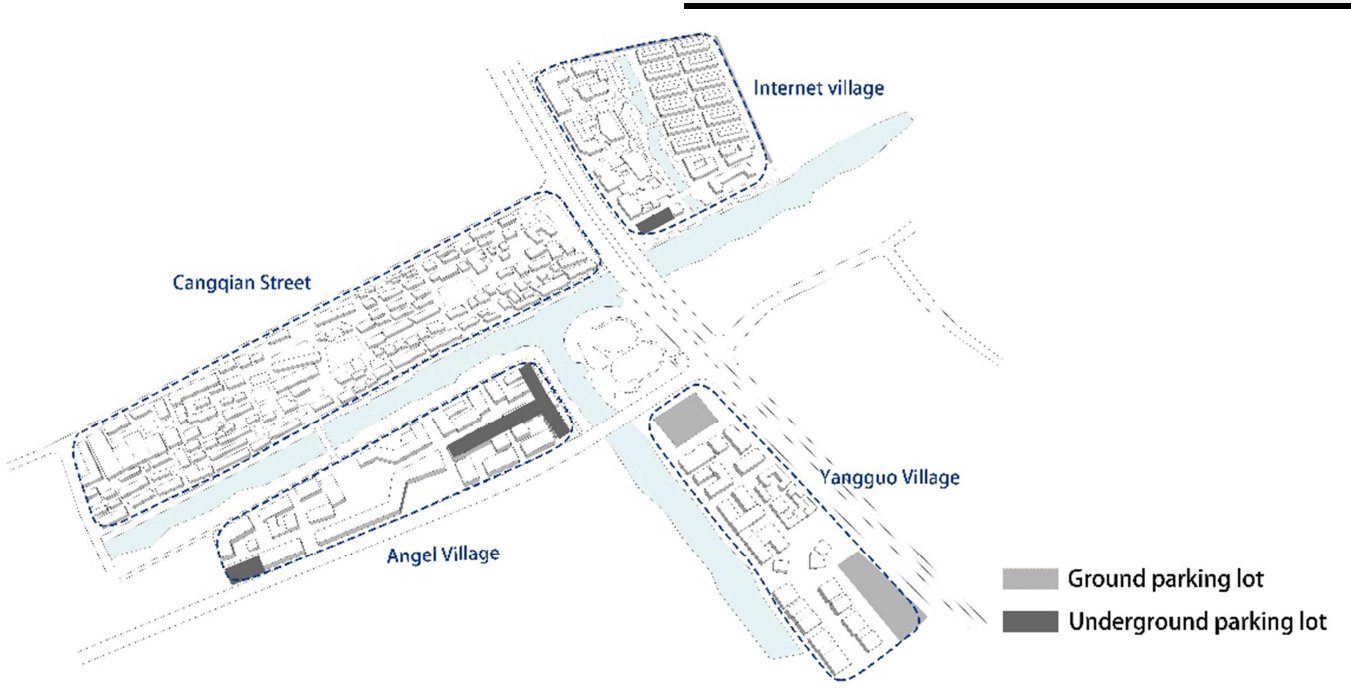

Figure 6. Static traffic analysis of the Dream Town.

\subsection{Optimization Strategy of Innovation Clusters}

\subsubsection{Policy Orientation}

The planning of an innovation cluster area should establish the policy of "government-led, enterprise-oriented, and market-oriented operation", and it should accurately define the relationship between the government, enterprises and markets. To better achieve the "government-led" aspect, it is necessary for the government to accurately locate and actively play its role.

The government must implement a policy system that is conducive to entrepreneurship and implement support policies such as tax and fee reductions, small-sum guaranteed loans, fund subsidies, and venue arrangements that encourage self-employment. At the same time, the government should also effectively perform entrepreneurship training and services, provide targeted policy support and entrepreneurial services for young entrepreneurs, support various training institutions to carry out entrepreneurship training, and build a business incubator base. In addition, the government must create a platform for entrepreneurial services, providing a full range of services, including government affairs, office affairs, and life support services, and introducing professional financial, legal, tax, and human resources.

In terms of facilities, the government should improve supporting living facilities, such as apartments, schools, supermarkets, and hospitals, and give entrepreneurs a zero-entry access policy and ample conditions, such as baggage, rent-free, and multisubsidy. The government also needs to provide entrepreneurs with low-cost, convenient, all-factor, open-ended entrepreneurial services to create a "common space" that is specialized, integrated, open, networked, living and convenient.

\subsubsection{Cooperation with Universities}

Innovation clusters can actively use the local media to enhance the influence of new media and provide promotional resources for the entrepreneurial team. At the same time, the innovation cluster area can also rely on the establishment of an industry-university-research platform between universities and organize more publicity and promotional activities in colleges and universities to enhance its popularity among college students.

To strengthen the interaction between innovation clusters and universities, they should set up technical output export and acceptance offices to strengthen technical cooperation and the transformation of results. Furthermore, innovation clusters can set up fund projects to support colleges and universities to research and explore Internet information technology. The research projects supported by the fund projects should be realistic, problem oriented and entrepreneurial.

At the same time, the government should formulate policies that encourage the interactive development of clusters such as the Dream Town and local universities. The government can measure the interactive development of 
innovation clusters and universities according to the contribution of innovation clusters to college employment, the degree of university technology transformation, the openness of universities to innovation clusters, and the promotion of entrepreneurship education.

\subsubsection{Space Optimization}

Innovative agglomeration area planning should fully consider the needs of entrepreneurs and indigenous residents in regard to life, leisure and entertainment, strengthen leisure places and increase the number of entertainment facilities. For example, in the case of the Dream Town, we propose to arrange fitness equipment in the small amusement park in the old street of Cangqian, to make full use of the riverside shops in the old street in Cangqian to carry out recreational activities, and to improve the configuration of public service facilities as soon as possible. Because the town is located in the relatively remote warehouse district, public transportation, food, entertainment and other infrastructure construction is still relatively backward, unable to meet the actual needs of entrepreneurs and college students. Thus, the government needs to speed up the construction of subways, shopping malls and parks. At the same time, planners can use the advantages of the Internet to improve community management efficiency and service quality. For example, by developing a public service app, users in the town can quickly find a garage with surplus parking spaces in the town.

The planning of innovative agglomeration areas must adapt to the requirements of new urbanization and focus on the coordinated development of industrial support, human settlements, social security and lifestyle. Planners should focus on building an innovation cluster into a new development space platform with distinctive industrial features, flexible institutional mechanisms, a strong humanistic atmosphere, a beautiful ecological environment and multiple functions.

\section{Conclusion}

The ability to innovate determines the core competitiveness of an enterprise, a region and even a country. The combination of technological innovation and industrial development definitely holds significance for promoting economic development. The driving force of economic development in today's world has shifted to technological innovation. A regional industrial technology innovation system can transform the model of regional industrial technology innovation through collaborative innovation. At the same time, a collaborative system provides most key technologies for regional industries, supports and leads regional industrial development, and enhances industrial technology innovation capability, which is key to industrial competitiveness. Through collaboration and cooperation, we can guarantee a better external environment and support conditions for the innovation system. Innovating collaborators can break the boundaries of departments, units and industries and finally reach effective collaborative innovation and realize the optimal allocation of innovation resources.

\section{Acknowledgements}

Many people have offered us valuable help in the paper writing, including our tutor, teachers and classmates.

First of all, we are extremely grateful for our instructor Professor Yang Jianjun for his careful guidance, warm encouragement and useful help in more than one year.

At the same time, we would also like to thank Professor Wang Jiwu, Associate Professor Xie Liangkui, Associate Professor Rao Chunkun, and Master Zhang Yuqi for their patient guidance on the development of the thesis.

Besides, we are pleased to acknowledge Dr. Fernanda Jahn-verri in the Department of Urban Planning and the UCLA Writing Center in University of California at Los Angeles for giving us guidance on English writing. Also, we want to express our thanks to the cooperation and guidance of the staff of Dream Town.

Then, we would like to thank the Zhejiang University Scientific Research Training Program for funding support and the Science and Technology Innovation Association of the College of Civil Engineering and Architecture.

Once again, we would like to express our heartfelt gratitude to all the people who have helped us. We can't complete the writing of this paper without their help in our scientific research.

\section{References}

[1] Haken H. Synergetics [M]. Berlin: Springer, 1978.

[2] Yang Qiugui. Research on Regional Innovation Environment Optimization Based on Synergetic Theory [J]. Caizhi, 2018 (11): 225 .

[3] Yang Xichun. Research on Regional Industrial Technology Innovation System Based on Collaborative Innovation Theory [J]. Journal of Chuzhou University, 2015, 25 (02): 26-33.

[4] VeronicaSerrano, Thomas Fischer. Collaborative innovation in ubiquitous systems [J]. International manufactur-ing, 2007, (18): 599-615.

[5] Duin H, Jaskov J, Hesmer A, Thoben K-D. Towards a framework for collaborative innovation [M]. Boston: Springer, 2008, 277: 193-204.

[6] Wang Jiwu, Liu Nina, Zhang Yuqi. Development Mechanism and Spatial Response of Innovation Cluster Area Based on Knowledge Spillover Effect-A Case Study of Zijin Zhongchuang Town of Zhejiang University [J]. Urban Development Research, 2018, 25 (11): 79-85.

[7] The Science and Technology Committee of the Ministry of Education, "China's Future and University Innovation" Strategic Research Group. China's Future and University Innovation (2011) [M]. Beijing: China Renmin University Press, 2011. 
[8] Chesbrough H W. Open Innovation [M]. Harvard Business School Press, Boston, MA, 2003.

[9] COOKE P, URANGA M, ETEXBARRIA G. Regional Innovation Systems Institutional and Organizational Dimension [J]. Research Policy, 2007 (26): 475-491.

[10] COOKE P, HANS J, BRAZYK H J, et a1. Regional Innovation Systems: The Role of Governance in the Globalized World [M]. London: UCL Press, 2006.

[11] ADNER R, KAPOOR R. Value creation in innovation eco-systems: How the structure of technological interdependence affects firm performance in new technology generations [J]. Strategic Management Journal, 2010 (31): 306-333.

[12] Wang Cong. Research on Regional Collaborative Innovation Network Based on Talent Aggregation Effect [M]. Beijing: Intellectual Property Publishing House, 2019

[13] KOSCHATZKY K, STERNBERG R. R\&D cooperation in innovation systems-Some lessons from the European Regional Innovation Survey [J]. European Planning Studies, 2000, 8 (04): 487-501.

[14] SHERIDAN C. Industry continues dabbling with open innovation models [J]. Nature Biotech nology, 2011, 29 (12): 1063-1065.
[15] Strat E J, Ketchen D J , Ireland R D, et al. Strategic entrepreneurship, collaborative innovation, and wealth creation [J]. Strategic Entrepreneurship Journal, 2010, 1 (3-4): 371-385.

[16] WANG Jiwu, ZHANG Yuqi, LIU Nina. Research on Innovation Cluster Area Planning Based on Innovation Ecosystem Theory [J]. Western Habitat Environment Journal, 2017, 32 (06): 46-50.

[17] Wu Rongbin. Operation and Constraints of University Liaison Window in Dream Town [J]. Innovation and Entrepreneurship Education, 2018 (4): 156-159.

[18] Wang Yongchang. The Great Stage of Big Dreams and Small Businesses-Thoughts on the Construction of Dream Towns and Characteristic Towns [J]. Zhejiang Economy, 2015 (13): $10-15$.

[19] Zhao Xuan, Zhang Weiliang, Lin Zhifeng. Research on the Interactive Development of Massive Space and Local Universities Based on Symbiosis Theory-Taking Dream Town and Hangzhou Normal University as Examples [J]. Innovation and Entrepreneurship Education, 2017, 8 (01): 44-47.

[20] Liu Shunying, Gao Liujian, Chuanlong. Design of supporting facilities in characteristic towns-Taking the planning and design of Dream Town and Yunqi Town as an example [J]. Garden, 2017 (1): 40-46. 